\title{
Analysis of protective features of concrete in precast prestressed floor slabs (HC type) against chloride penetration
}

\author{
Zofia Szweda ${ }^{1, *}$ \\ ${ }^{1}$ Department of Building Structures, Silesian University of Technology, Akademicka 5, 44-100 \\ Gliwice, Poland
}

\begin{abstract}
This paper describes protective features of concrete used in precast prestressed floor slabs against chloride penetration. HC-500 hollow core slabs are designed for constructing ceilings in skeletal buildings with reinforced concrete. Material and structural protection used in slabs determines the acceptable range of using $\mathrm{HC}$ slabs, taking into account durability of floors during their normal exploitation. These slabs can be used in buildings where environmental conditions affect them according to the following exposure classes: $\mathrm{X} 0, \mathrm{XC} 1, \mathrm{XC} 2, \mathrm{XC} 3$ (according to standards: EN 206-1: 2003 [1], EN 1992-1-1:2004 [2]). Values of diffusion coefficient for concrete collected directly from precast prestressed HC-500 slabs, were determined during short ( $24 \mathrm{~h}$ and $48 \mathrm{~h})$ tests accelerated by the electric field. In those tests we used a thermodynamic migration model and a reverse equation of chloride migration in concrete. Taking into consideration values of diffusion coefficient and diffusion equation, the time required for chloride concentration to reach critical value for reinforcement and the thickness of reinforcement cover were established under the condition that the structure durability was subjected to the exposure class XD3 (chapter 4 of the standard PN 1992-1-1[2]).
\end{abstract}

\section{Introduction}

Wide-span floor systems can be used to construct one-space interior with many functional qualities. Such floor systems facilitate very quick assembly of a construction, without using shuttering and supports that prevent creeping. Consequently, we obtain significant economic benefits and become independent of atmospheric conditions [3]. Nowadays, a variety of hollow core slabs produced in Poland is growing. The described HC-500 slabs were precast prestressed elements for floors in buildings of different type and construction. According to [4], HC slabs should be mainly used in frame constructions with reinforced concrete or steel structure while maintaining the fundamental static nature of a slab as a freely supported beam. HC-500 slabs covering the maximum span of $21 \mathrm{~m}$ are recommended for warehouses, industrial and commercial buildings, and service buildings. The slabs were made of C50/60 concrete, w/c = 0.3, with Portland cement CEM II 52.5 R. Material and structural shielding

\footnotetext{
* Corresponding author: zofia.szweda@polsl.pl
} 
of the slabs: concrete class, cement type and content in concrete, cover thickness of prestressing tendons; determines the permissible application of HC slabs regarding floor durability during standard operation. Such slabs can be exclusively used in facilities where environmental conditions (corrosion inducing agent) directly affect the slabs and correspond to the following exposure classes: X0, XC1, XC2 i XC3 (according to standards: EN $1992-$ 1-1:2004 [2], EN 206-1: 2003 [1]).

EN 1992-1-1:2004 [2] standard specifies the permissible critical concentration of chloride ions $\left(\mathrm{C}_{\mathrm{K}}=0.1\right.$ or $0.2 \%$ by cement weight $)$ in prestressed constructions. Due to safety reasons, this value is lower than in case of reinforced concrete structure. British standard BS 8110: Part 1: 1997 [5] limits the maximum concentration of chlorides from all composition materials to the level of $0.1 \div 0.4 \%$ by cement content depending on the used type of reinforcement, cement and concrete. American standard ACI 318M-02/318RM02 [6] specifies the maximum content of chloride ions in concrete as $0.06 \%$ of cement weight in prestressed concrete elements, where concrete is in direct contact with prestressed steel [7].

The purpose of this paper was to determine values of chloride diffusion coefficient for concrete directly drilled from precast prestressed concrete slabs HC-500. To determine the coefficient, we performed short ( 24 and 48 -hour) tests accelerated by the electric field and applied a thermodynamic migration model with the inverse problem of the equation for chloride migration in concrete [8]. Considering values of determined coefficients and the solved equation for diffusion, we defined time after which chloride concentration could reach its critical value on the reinforcement surface. We also specified the cover thickness for a structure with the given durability (50 years), structural class S4 and exposure class XD 3 cyclic wet and dry environment, parts of bridges exposed to spray containing chlorides, pavements, car park slabs (in accordance with Chapter 4, PN 1992-1-1 [2]).

\section{Experimentally determined and calculated diffusion coefficient}

The tests were performed on elements drilled directly from the top surface of precast prestressed floor slabs HC-500, using a diamond drilling machine with a diameter of $8 \mathrm{~cm}$ (Fig. 1). The slabs were produced from the concrete mix specified in Table 1 [4].

Table 1. Components of concrete mix and average compressive strength of concrete $\mathrm{f}_{\mathrm{ctm}}$.

\begin{tabular}{|c|c|c|c|c|}
\hline Concrete & Components & $\begin{array}{c}\text { Mass } \\
{\left[\mathrm{kg} / \mathrm{m}^{3}\right]}\end{array}$ & w/c & $\begin{array}{c}\mathrm{f}_{\mathrm{cm}} \\
{[\mathrm{MPa}]}\end{array}$ \\
\hline \multirow{4}{*}{ C50/60 } & Cement Cem II A-S 52.5 & 550 & \multirow{3}{*}{} & \\
& Crushed BASALT & 1304 & \multirow{3}{*}{0.31} & \multirow{3}{*}{65} \\
\cline { 2 - 3 } & Sand & 580 & \\
& Superplasticizer & 6.24 & & \\
\cline { 2 - 3 } & Water & 149 & & \\
\hline
\end{tabular}

The tests were performed on six cylindrical specimens with a diameter of $80 \mathrm{~mm}$ and height of $50 \mathrm{~mm}$, whose side surfaces were coated with resin to ensure unidirectional flow of chloride ions. Containers with $3 \% \mathrm{NaCl}$ solution were attached firmly to the top surface of cylindrical specimens. Stainless steel cathodes with a size adjusted to cross section of cylindrical elements, were placed inside the containers. The tests were simultaneously performed on three specimens connected in parallel to form the electric circuit (Fig. 1a). They were placed on a wet sponge below which a platinum-plated titanium mesh anode was. The specimens were soaked in distilled water for 72 hours to increase electrical conductivity of concrete. Then, a set of specimens was connected to direct current supply with voltage $U=$ $18 \mathrm{~V}$. The tests on chloride migration were performed for two times $\mathrm{t}_{1}=24$ and $\mathrm{t}_{2}=48$ hours. $\mathrm{NaCl}$ solution was replaced after 24 hours. During the whole period of tests, the temperature 
of solution was constant, at about $20^{\circ} \mathrm{C}$. When the migration process was completed, the specimens were left under ambient conditions for 72 hours. Concrete powder was collected from each specimen, from 10 consecutive depth increments of thickness $\mathrm{g}=2 \mathrm{~mm}$ using "Profile Grinding Kit" from German Instruments AS company. We aggregated powder concrete from three similar specimens and added distilled water in a 1:1 weight ratio. That dense solution was stirred every few hours per 24 hours, and then passed through a medium-sized filter. Washing out was repeated twice. The experimental solutions were subjected to chemical analysis to determine concentration $\mathrm{c}^{1}\left[\mathrm{mg} / \mathrm{dm}^{3}\right]$ of chloride ions in the liquid by argentometric titration in accordance with the Mohr's method (standard ISO 9297) [9] - Table 2.

Water in a 1:1 weight ratio was used to wash out powder concrete twice. Water weight by volume $\gamma_{w}=1 \mathrm{~kg} / \mathrm{dm}^{3}$ was used to estimate volume $V_{r}$ of the experimental liquid, and then to determine mass density $\varrho^{l}$ of chloride ions [8].

$$
\rho^{l}=\frac{m^{l}}{V_{c}}=\frac{2 c^{l} \gamma_{c}}{\gamma_{w}}
$$

Table 2 presents calculated results for mass density $Q^{l}$ of chloride ions migrating in concrete specimens under the electric field.

Table 2. Concentration $\mathrm{c}^{1}$ in the experimental solution and mass density $\rho^{1}$ in concrete - migration of ions $\mathrm{Cl}^{-}$under the electric field.

\begin{tabular}{|c|c|c|c|c|c|}
\hline \multirow{2}{*}{$\begin{array}{c}\text { Interval } \\
{[\mathrm{mm}]}\end{array}$} & \multirow{2}{*}{$\begin{array}{c}\text { Coordinate } \\
{[\mathrm{mm}]}\end{array}$} & \multicolumn{2}{|c|}{$\begin{array}{c}\mathrm{Cl}^{-} \text {Concentration in solution } \mathrm{c}^{1} \\
{\left[\mathrm{mg} / \mathrm{dm}^{3}\right]}\end{array}$} & $\begin{array}{c}\text { Density of mass } \mathrm{Cl}^{-} \\
\text {in concrete } \rho^{1} \\
{\left[\mathrm{~kg} / \mathrm{m}^{3}\right]}\end{array}$ \\
\cline { 3 - 6 } & & $\mathrm{t}_{1}=24 \mathrm{~h}$ & $\mathrm{t}_{2}=48 \mathrm{~h}$ & $\mathrm{t}_{1}=24 \mathrm{~h}$ & $\mathrm{t}_{2}=48 \mathrm{~h}$ \\
\hline $0 \div 2$ & 1 & 306.60 & 577.6 & 1.61 & 3.03 \\
\hline $2 \div 4$ & 3 & 114.10 & 57.8 & 0.60 & 0.30 \\
\hline $4 \div 6$ & 5 & 40.30 & 29 & 0.21 & 0.15 \\
\hline $6 \div 8$ & 7 & 24.60 & 14.3 & 0.13 & 0.07 \\
\hline $8 \div 10$ & 9 & 18.60 & 14.1 & 0.10 & 0.07 \\
\hline $10 \div 12$ & 11 & 13.10 & 12.1 & 0.07 & 0.06 \\
\hline $12 \div 14$ & 13 & 16.00 & 15.4 & 0.08 & 0.08 \\
\hline $14 \div 16$ & 15 & 5.30 & 4.9 & 0.03 & 0.03 \\
\hline $16 \div 18$ & 17 & 1.80 & 8 & 0.01 & 0.04 \\
\hline
\end{tabular}

Chloride ions migrate in concrete through liquid present in pores containing dissolved components of hydrated cement. We used the thermodynamic model of chloride ingress in concrete described in the paper [8], to analyse ion flow in pore solution. We identified a theoretical representative of volume X - Fig. 1c, and then defined concrete structure with water-filled pore space as an inert component $\alpha=0$ which was not directly involved in the process. The following anions $\mathrm{Cl}^{-}-\alpha=1, \mathrm{OH}^{-}-\alpha=2$ and cations $\mathrm{Na}^{+}-\alpha=3, \mathrm{~K}^{+}-\alpha=4$ and $\mathrm{Ca}^{2+}-\alpha=5$ were the components involved into this process. 


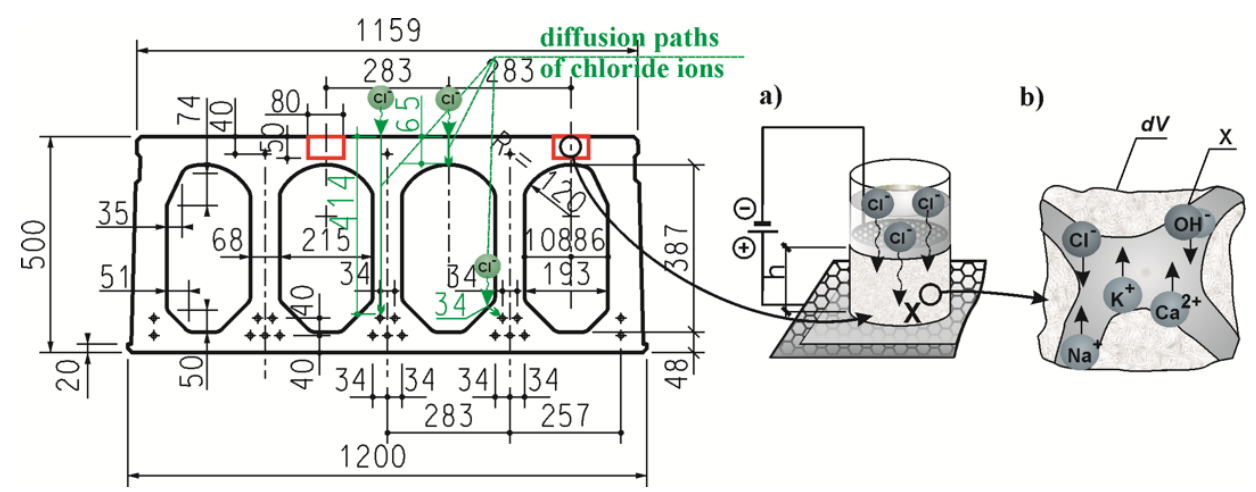

Fig. 1. Cross-section of HC500-19/R120 precast prestressed floor slabs and paths of chloride ion diffusion to prestressing tendons. The model of ion ingress in concrete: a) electrical scheme, b) the process components in the representative volume element.

The sample was parametrised with the coordinate system, where the top surface in contact with chloride solution corresponded to the plane $\mathrm{x}=0$, whereas the plane $\mathrm{x}=\mathrm{h}$ specified the location of its bottom part. To determine experimentally the distribution of chloride ion concentrations $\rho^{1}(x)$, the powder material was collected from the depth increments of a specimen. The places, for which concentrations were determined experimentally, were located within the distance a from the top surface of the specimen. Concentration distributions were determined for $t_{1}$ and $t_{2}>t_{1}$ during the time period of migration. Considering voltage $U$ between the electrodes, we assumed potential $\varphi(0)=U$ at point $x=0$ and $\varphi(h)=0$ at bottom of the specimen(coordinate $x=h$ ). The potential distribution along the specimen height was approximated by the linear function.

As a result conversions, we obtained an expression determining the coefficient diffusion of chloride ions $\mathrm{D}^{1}=1 / \mathrm{Q}$, that is, the converse diffusion resistance for the whole tested zone of the concrete within the range a

$$
D^{l}=\frac{\bar{j}^{l}(a) a \Delta t}{\frac{z^{l} F U g}{R T h}\left[\bar{\rho}_{1}{ }_{1}+\bar{\rho}_{2}{ }_{2}^{1}+\ldots+\bar{\rho}_{n}^{l}\right] \Delta t-B} B=\int_{0}^{a} Q_{x}\left[\rho^{l}(x, t+\Delta t)-\rho^{l}(x, t)\right] d x
$$

where $\bar{j}^{1}(a)$ is the value of chloride ions flowing through the plane within the distance $\mathrm{x}=\mathrm{a}$ (Fig. 3), $\bar{\rho}_{1}^{1}, \bar{\rho}_{2}^{1}$, and $\bar{\rho}_{\mathrm{n}}^{1}$ densities of $\mathrm{Cl}^{-}$at midpoints of consecutive intervals [0, $\mathrm{g}],[\mathrm{g}, 2 \mathrm{~g}], \ldots,[(\mathrm{n}-1) \mathrm{g}, \mathrm{a}]$ averaged over time $\Delta \mathrm{t}$. The first term of the dominator determines the steady state of chloride ion flow, whereas the second one - B refers to the non-steady state [8].

On the basis of measured mass distribution $\rho^{1}$ of chloride ions migrating in concrete under the electric field, we obtained the reliable value of diffusion coefficient from the relation (2). Calculated results are presented in Table 3. 
Table 3. Calculated results for the diffusion coefficient of ions $\mathrm{Cl}^{-}$.

\begin{tabular}{|c|c|c|c|c|c|c|c|}
\hline \multirow{3}{*}{ Zone } & \multirow{3}{*}{$\mathrm{t}[\mathrm{h}]$} & \multirow{3}{*}{$\begin{array}{c}\mathrm{D}_{\mathrm{s}}^{1} \\
\cdot 10^{12} \\
{\left[\mathrm{~m}^{2} / \mathrm{s}\right]}\end{array}$} & \multicolumn{5}{|c|}{$\mathrm{D}_{\mathrm{ns}}^{1} \cdot 10^{12}\left[\mathrm{~m}^{2} / \mathrm{s}\right]$} \\
\hline & & & \multicolumn{5}{|c|}{ Non-stationary influence } \\
\hline & & & $10 \%$ & $20 \%$ & $30 \%$ & $40 \%$ & $50 \%$ \\
\hline \multirow[t]{2}{*}{ I } & 24 & 0.05 & 0.06 & 0.07 & 0.08 & 0.09 & 0.11 \\
\hline & 48 & 0.14 & 0.16 & 0.19 & 0.20 & 0.24 & 0.29 \\
\hline \multirow[t]{2}{*}{ II } & 24 & 0.3 & 0.33 & 0.39 & 0.42 & 0.51 & 0.61 \\
\hline & 48 & 0.2 & 0.22 & 0.26 & 0.28 & 0.35 & 0.41 \\
\hline \multirow{2}{*}{ III } & 24 & 0.87 & 0.96 & 1.13 & 1.22 & 1.48 & 1.74 \\
\hline & 48 & 0.39 & 0.43 & 0.51 & 0.55 & 0.66 & 0.78 \\
\hline \multirow[t]{2}{*}{ IV } & 24 & 1.17 & 1.28 & 1.52 & 1.63 & 1.98 & 2.33 \\
\hline & 48 & 0.47 & 0.52 & 0.62 & 0.66 & 0.80 & 0.95 \\
\hline \multirow[t]{2}{*}{$\mathrm{V}$} & 24 & 1.47 & 1.61 & 1.91 & 2.05 & 2.49 & 2.93 \\
\hline & 48 & 0.52 & 0.57 & 0.68 & 0.73 & 0.89 & 1.04 \\
\hline \multirow{2}{*}{ VI } & 24 & 1.68 & 1.85 & 2.18 & 2.35 & 2.85 & 3.36 \\
\hline & 48 & 0.5 & 0.55 & 0.66 & 0.71 & 0.86 & 1.01 \\
\hline \multirow{2}{*}{ VII } & 24 & 1.85 & 2.03 & 2.40 & 2.59 & 3.14 & 3.70 \\
\hline & 48 & 0.5 & 0.57 & 0.68 & 0.73 & 0.89 & 1.04 \\
\hline \multirow[t]{2}{*}{ VIII } & 24 & 2.48 & 2.72 & 3.22 & 3.47 & 4.21 & 4.95 \\
\hline & 48 & 0.44 & 0.48 & 0.57 & 0.61 & 0.74 & 0.87 \\
\hline \multicolumn{2}{|c|}{$\overline{\mathrm{D}} 1$} & 0.72 & 0.79 & 0.94 & 1.01 & 1.22 & 1.44 \\
\hline
\end{tabular}

The obtained value of diffusion coefficient $\bar{D}_{s}^{1}=0,72 \cdot 10^{-12} \mathrm{~m}^{2} / \mathrm{s}$ n for the steady state of the tested concrete classified the tested concrete to the group with very low chloride permeability $[8,10,11,12]$. The parameters of the tested concrete were superior to the requirements of the standard EN 206-1 [1] in terms of minimum values of concrete durability, cement content and $\mathrm{w} / \mathrm{c}$ ratio required for the analysed exposure class XD3.

\section{Determination of protective features of concrete used in precast prestressed floor slabs (HC type) against chloride penetration}

Protective properties of concrete cover were determined by calculating an increase of chloride ion concentration from experimentally determined diffusion coefficient for concrete that had been directly collected from precast prestressed floor slabs HC500-19/R120. For calculations we used concrete cover $\mathrm{c}_{\text {nom }}=35 \mathrm{~mm}$ for tendons $\varnothing 9.3$ made of steel Y1860, typical for those hollow-core slabs. The tendons formed the top reinforcement protecting concrete on the top surface of prefabricated units against cracking in the initial stage, directly after compression, and they protected long slabs against breaking down while they were lifted. Additionally, we determined the cover $\mathrm{c}_{\mathrm{nom}}=55 \mathrm{~mm}$ according to Table $4.5 \mathrm{~N}$, EN 1992-1-1 Eurocode 2 [2] assuming the structure durability (50 years) for structural class S4 and exposure class XD3 - cyclic wet and dry environment, parts of bridges exposed to spray containing chlorides, pavements, car park slabs. Diffusion coefficients of chlorides in steady state conditions was used for calculations because, according to the tests on concrete performed by the author $[8,10,12]$, reliable values of diffusion coefficient could be obtained after six-month diffusion under steady state conditions. According to EN 1992-1-1 Eurocode 
2 [2], prestressing tendons in the top part of a slab were prone to corrosion induced by chloride ions reaching the critical concentration was $C_{K}=0.2 \%$ by cement mass. We also determined the shortest path of chloride ion ingress in prestressing tendons with a diameter $\varnothing 12,5$ (Fig. 1) located in the bottom part of a slab. That path was a sum of thickness of a top slab in the structural-floor tile $-65 \mathrm{~mm}$ and a tendon cover at the inner side of the hollow core - $34 \mathrm{~mm}$ (Czarnecki, Wojciechowski 2014[7]. Corrosion risk for tendons in the bottom part of main reinforcement was assumed to be induced by critical concentration of chloride ions equal to 0.1\% according to EN 1992-1-1 Eurocode 2 [2].

Changes in chloride concentration between reinforcement and concrete cover $\mathrm{x}=35, \mathrm{x}=$ 55 and $\mathrm{x}=99 \mathrm{~mm}$ were calculated according to the known solution for diffusion equation [7, $12,13]$

$$
\rho_{c a l}^{l}(x=35,55 ; t)=\rho_{0, c a l}^{l}\left(1-\operatorname{erf} \frac{x}{2 \sqrt{D_{n s}^{l} t}}\right)
$$

where $\rho_{0, c a l}^{l}$ is the calculated mass density of chlorides at the the element boundary, erf - the Gauss error function, $\mathrm{t}$ - time.

Mass density of chloride ions $\rho^{l}(x=35,55,99 ; t)$ cal was referred to constant density of cement mass $\rho_{\text {cem }}$ in concrete by determining relative concentration of chlorides

$$
C^{l}(t)=\frac{\rho^{l}(x=(35 ; 55 ; 99), t)_{c a l}}{\rho_{\text {cem }}} 100 \%
$$

Chloride concentration equal to $C_{0}^{l}=0,8 \%$ by cement weight was assumed at concrete edge. Changes in chloride concentration over time $t$ were computer determined. These changes are illustrated in Fig. 2.

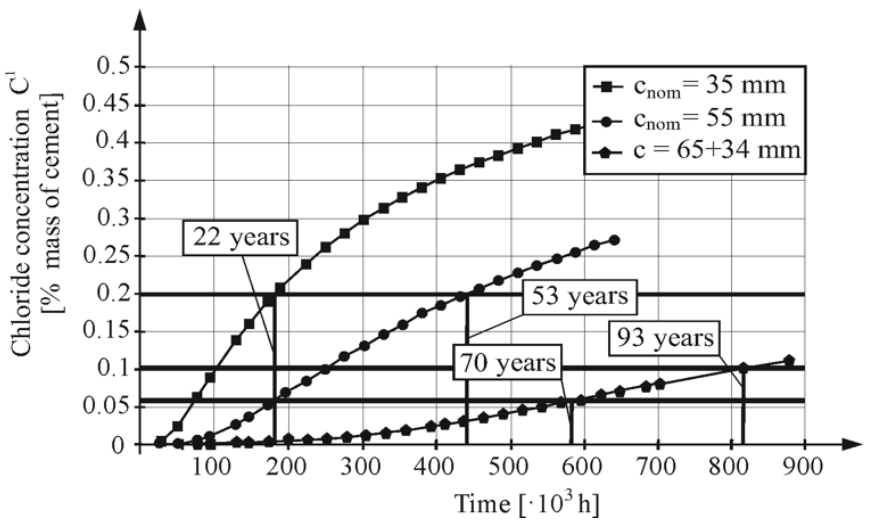

Fig. 2. Time-dependent changes of chloride concentration in concrete-steel contact zone for three different thickness values $(35,55$ and $99 \mathrm{~mm})$ of concrete coatings of steel prestressing tendons.

They referred to the interface between prestressing tendons in the top part of concrete and concrete cover - $35 \mathrm{~mm}$ and $55 \mathrm{~mm}$, respectively, and for the shortest determined path of chloride ingress in lower edges of prestressing tendons in the main reinforcement $-99 \mathrm{~mm}$. Time, after which prestressing tendons were prone to corrosion, was specified by comparing chloride concentration to the critical value. Corrosion risk for top tendons will appear after 
22 years of the structure operation providing that cover thickness is $35 \mathrm{~mm}$. The minimum thickness of cover for top tendons for structural class S4 and exposure class XD3, that is, the thickness of $55 \mathrm{~mm}$ would protect upper tendons against corrosion for 53 years. Assuming that chloride ions penetrate bottom tendons from the top surface of floor slab, and the limit value of chloride concentration is $C_{K}=0.1$, corrosion of tendons is possible after 93 years of operation. For the limit value of chloride concentration $C_{K}=0.06$, bottom tendons will corrode after 70 years (Fig. 2).

\section{Conclusions}

On the basis of the accelerated tests performed on chloride ion migration into cylindrical elements drilled directly from the top surface of precast prestressed floor slabs HC50019/R120, we determined the diffusion coefficient of chloride ions in concrete used to produce the analysed slabs. Changes in chloride concentration over time were determined for the shortest ingress path of chloride ions at the interface between top prestressing tendons and concrete cover used in such slabs, for the cover of minimum thickness recommended for XD3 class, and on the surface of bottom prestressing tendons. We determined time periods, after which those tendons could corrode assuming that penetration of chloride ions would be observed only at the surface of the top floor slab.

It may be difficult to draw firm conclusions about the predicted durability of analysed slabs on the basis of the obtained results. Due to the complex work of top and bottom tendons in the prestressed structure, the detailed static analysis should be performed. Its scope should include the possible scenario of tendons unbonded to concrete because of corrosion, and the resulting effect on bearing capacity of bottom tendons. The analysis of slab bearing capacity depending on thickness of used concrete cover is also required [14].

Critical value of $\mathrm{Cl}^{-}$concentration is not clearly specified and depends on numerous factors, such as: a type of cement, $\mathrm{C}_{3} \mathrm{~A}$ content in cement, a type of concrete mix, w/c ratio, a type of steel surface. Therefore, tests on the development of corrosion risk are needed. They should involve the following electrochemical techniques: Electrochemical Impedance Spectroscopy (EIS) and Linear Polarization Resistance (LPR), and should indicate concentration of chloride ions on the steel surface of prestressing tendons that induces corrosion in the specimens drilled directly from the tested floor slabs [15]. Values of diffusion and migration coefficients for elements drilled from the described slabs should be also determined on the basis of binding European standards [16].

\section{References}

1. PN-EN 206-1

2. PN-EN 1992-1-1

3. A. Ajdukiewicz, J. Mames, Konstrukcje z betonu sprężonego (PC, Kraków, 2004)

4. G. Troszczyński, Wytyczne projektowania stropów z plyt sprężonych „HC”. Poradnik dla projektantów (Steelco, 2013)

5. BS 8110: Part 1: 1997 (1998)

6. ACI 318M-02/318RM02 (2002)

7. L. Czarnecki, P. Woyciechowski, XIII Konferencja Naukowo-Techniczna, 102-124 (WPRB, 2014)

8. Z. Szweda, A. Zybura, Procedia Eng. 57, 1121-1130 (2013)

9. PN-ISO 9297 
10. Z. Szweda, Badania oporu wnikania chlorków do betonu na cementach portlandzkim zwyktym i niskoalkalicznym, 148-153(OpK, 2016)

11. Z. Szweda, Roczniki Inżynierii Budowlanej, 79-86, (2016)

12. Z. Szweda, T. Ponikiewski, J. Katzer, J. of Clean. Prod. 156, 569-576, (2017)

13. Z. Szweda, A. Śliwka, 12th Central European Congress on Concrete Engineering CCC 2017, 118-126 (2017)

14. Z. Szweda, A. Śliwka, Procedia Eng. 193, 417-422 (2017)

15. T. Jaśniok, M. Jaśniok, Procedia Eng. 108, 316-323 (2015)

16. Z. Szweda, Wybrane zagadnienia teoretyczne i doświadczalne $w$ badaniach materiałów i konstrukcji budowlanych, 451-463 (Gliwice, 2017) 